BMJ Open Sport \& Exercise Medicine

\title{
The incidence of injury in elite camogie, an in-season prospective study
}

Catherine Susan Buckley, Catherine Blake

To cite: Buckley CS, Blake C. The incidence of injury in elite camogie, an in-season prospective study. BMJ Open Sport \& Exercise Medicine 2018:4:e000315. doi:10.1136/ bmjsem-2017-000315

Accepted 30 March 2018
Check for updates

School of Public Health, Physiotherapy and Sport Science, University College Dublin, Dublin, Ireland

\section{Correspondence to} Catherine Susan Buckley, Rena Buckley Chartered Physiotherapy Clinic, Cork Street, Macroom, Co Cork P12 YE86, Ireland; info@ renabuckleyphysio.ie

\section{ABSTRACT}

Background Camogie is a stickhandling, high-velocity, multidirectional field sport for females which is native to Ireland, but is also played internationally.

Aim To establish the incidence, nature and severity of injuries in elite camogie players.

Methods A prospective, observational cohort study was carried out during the Provincial Championships and extending into the All-Ireland Championship until a participating team was eliminated (11 weeks). A purposive sample of 62 players from 3 of the total 11 senior intercounty teams participated to generate geographical representation. Injury data were recorded and classified by team physiotherapists using a time loss definition, consistent with consensus statements. A concurrent measure of exposure to matches and training was recorded.

Results Twenty-one incidents of injury were recorded with 14 players injured. Injury incidence rate was 26.4 (95\% Cl 13.44 to 47.16$)$ per 1000 match hours and 4.2 $(95 \% \mathrm{Cl} 2.12$ to 7.46$)$ per 1000 training hours. There were 11 contact and 10 non-contact injuries. The lower limb accounted for $71.4 \%(n=15)$, the upper limb $9.5 \%$ $(n=2)$ and the trunk and head $19.1 \%(n=4)$ of injuries. The main tissues injured were both muscle and ligament, representing $57.2 \%$ ( $n=6$ each). The mean duration time loss from sport per injury was 12.14 days.

Conclusion These results provide data on the incidence, nature and severity of camogie injuries using definitions that reflect international consensus statements. Further study of injury incidence over a full season or multiple seasons is recommended.

\section{INTRODUCTION}

Camogie is a stickhandling, high-velocity, multidirectional field sport which is native to Ireland. It is also played internationally in North America, Britain, continental Europe, Asia/Gulf region and Australia. ${ }^{1}$ It is the female version of hurling, one of the four sports of the Gaelic Athletic Association. There are a few rule differences between the two sports, but they are similar in terms of skill and physical demands. There are over 71000 members of An Cumann Camógaíochta (The Camogie Association) in Ireland, making it the second largest women's sport in the country. ${ }^{2}$

\section{What are the new findings?}

These data provide information on incidence, mechanism, severity and nature of injury in senior intercounty camogie.

- The mean duration time loss from sport was 12.14 days ranging from 3 days to 56 days per injury.

- Incidence of injury was $26.4 / 1000$ hours of match play and 4.2/1000 hours of training.

- Injury definitions used are consistent with consensus statements for other sports such as hurling, Gaelic football and soccer.

Camogie, like hurling, is played on a rectangular grass pitch 130-145 m long and 80-90 m wide. Goal posts with a crossbar are located at either end of the field. Two teams of 14 outfield players and a goalkeeper compete against each other in a 60-min match, comprised of two 30-min periods. Five substitutions are permitted per team. Players attempt to play a hard leather ball (sliotar) through their opponent's goalposts using a hurley made of ash timber, either below the crossbar for a goal (three points) or above the crossbar for a point. Players may strike, hand pass, solo or kick the sliotar and may block, flick or hook the opponent's hurley when not in possession of the sliotar. ${ }^{3}$ The sliotar moves quickly and can reach speeds of up to $112 \mathrm{~km} /$ hour. $^{4}$ Players accelerate, decelerate, jump, land and change direction while playing camogie, movements which put players at risk of injury to the lower limb. ${ }^{56}$ Injury can also occur due to direct force from another player, a hurley, the sliotar or the ground. Intercounty camogie is the highest level of competition, with the best players from club teams selected to represent their respective counties.

The camogie intercounty season includes the National Senior Camogie League from February until April, the Provincial Championships in May and the All-Ireland Senior Camogie Championship (the most prestigious competition) from June until September. Intercounty camogie teams usually have collective on-field 90 min training sessions two 
to three times per week and play a match at the weekend. Physical conditioning training varies between teams.

At present, there are no prospective data to indicate injury incidence in camogie at any level. A previous study focused on injuries presenting to a hospital emergency department, ${ }^{7}$ but this study dates back to 1989 . There have since been changes in the rules of camogie, including the compulsory wearing of a helmet, changes to the competition structures as well as a change in training techniques and the general style of play, which may influence the incidence, nature and severity of injuries. ${ }^{3}$ Comprehensive studies have been carried out recently in camogie's male equivalent game of hurling. ${ }^{89}$ These provide an excellent record of incidence, nature and mechanism of injury in senior intercounty hurling. However, differences exist in the rules and competition structures between camogie and hurling. There are differences in the incidence of injury in the male and female versions of Gaelic football ${ }^{10}$ and ice hockey, ${ }^{11}$ which may be due to rule differences in the respective games. The injury rate in male and female soccer is similar, but the nature of injury sustained by males and females differ somewhat. ${ }^{12}{ }^{13}$ As the rules in soccer are the same for both males and females, this may be due to innate differences between the sexes. ${ }^{14}$ These discrepancies in injury incidence and nature between male and female versions of the same sport and the gap in injury epidemiology data in camogie warrant further investigation.

This study, the first of its kind, aims to establish the incidence, nature and severity of injury in intercounty camogie. Describing injury profile is important in all sports. It is the first step van Mechelen $e a^{15}$ used in their 'sequence of prevention' model of sports injuries.

\section{METHODS}

The surveillance period focused on the premier competition phase of the season, encompassing the Provincial Championships and the All-Ireland Championship until the knockout stages. This resulted in an 11-week time span from 1 May until 16 July.

A purposive sample from all 11 teams participating in the 2016 Senior Inter-County Camogie Championship was sought to get geographical representation. One team from each of the four provinces was selected to participate. Inclusion criteria for player participation was being a member of the senior intercounty panel (squad).

All players, both adult and those under 18 years, were informed of the details of the study and informed consent was obtained from players and parents/guardians of those under 18 years. All data recorded were coded and player anonymity was preserved. Injury was defined as a time-loss injury, that is, 'any injury that prevents a player from taking a full part in all training and match play activities typically planned for that day, where the injury has been there for a period greater than $24 \mathrm{~h}$ from midnight at the end of the day that the injury was sustained'. This definition used by Brooks et $a l^{16}$ has been used previously in studies relating to injury in hurling. ${ }^{89}$ It also conforms to the consensus for time-loss injury definitions proposed for the soccer and rugby union. ${ }^{1718}$ Injuries were classified as new, if this was the first incident of injury, or recurrent, if located in the same site and involving the same tissue as the previous injury, with the time since the last incidence of injury recorded in line with the description by van Mechelen $e t$ al. ${ }^{15}$ Contact injury was described if there was direct contact with either another player, hurley/sliotar or the ground. Non-contact injury was recorded if the injury occurred without contact as above, for example, in turning/cutting, sprinting, landing or push-off actions. Overuse injury was described if there was no history of a single inciting event, but a gradual onset with worsening over-repeated exposure to training or match play. ${ }^{15}$

At the beginning of the study, the participating players provided their demographic details (age, height, weight, occupation, position of play) and their history of previous injuries sustained. The team physiotherapist recorded each new injury as the player presented for treatment using a standard injury recording form. The date of the injury, mechanism of injury, main tissue injured, body region injured, whether the injury was new or recurrent, clinical diagnosis, number of days injured and date of return to play were recorded on a hard copy. The team manager recorded the number and duration of all training sessions and matches played (competitive and non-competitive) over the 11-week period on a standard recording sheet, permitting calculation of exposure hours. All data were collated by the researcher at the end of the camogie season.

Data were analysed with IBM SPSS V.24 (IBM released 2016). ${ }^{19}$ The injury rate per 1000 hours of training and match play and the average number of injuries per team were calculated. Means with SD were calculated for continuous variables. Percentages with $95 \%$ CIs were calculated to describe the different mechanisms of injury, tissue type injured, body region injured and whether the injury was new or recurrent.

\section{RESULTS}

Three of the four teams selected complied fully with the data collection and 62 players from these were followed during the 2016 Senior Inter-County Camogie Championship. The mean age of the players studied was 22.9

\begin{tabular}{|c|c|c|c|c|}
\hline Location & $\begin{array}{l}\text { Exposure } \\
\text { time } \\
\text { (hours) }\end{array}$ & $\begin{array}{l}\text { No. of } \\
\text { injuries }\end{array}$ & $\begin{array}{l}\text { Injuries per } \\
1000 \text { hours }\end{array}$ & $95 \% \mathrm{Cl}$ \\
\hline Match play & 378 & 10 & 26.4 & 13.44 to 47.16 \\
\hline $\begin{array}{l}\text { Training } \\
\text { session }\end{array}$ & 2391 & 10 & 4.2 & 2.12 to 7.46 \\
\hline Other* & & 1 & & \\
\hline Total & 2769 & 21 & 7.6 & 4.82 to 11.4 \\
\hline
\end{tabular}

*Injury which cannot be attributed to a single match or training incident. 


\begin{tabular}{|c|c|c|c|c|c|c|}
\hline Location & n (\%) & $95 \% \mathrm{Cl}$ & Contact n (\%) & $95 \% \mathrm{Cl}$ & Non-contact n (\%) & $95 \% \mathrm{Cl}$ \\
\hline Match play-county & $4(19.1)$ & 6.3 to 42.6 & $2(9.5)$ & 1.7 to 31.8 & $2(9.5)$ & 1.7 to 31.8 \\
\hline Match play-club & $6(28.6)$ & 12.2 to 52.3 & $6(28.6)$ & 12.2 to 52.3 & $0(0)$ & \\
\hline Training session & $10(47.6)$ & 26.4 to 69.7 & $3(14.3)$ & 3.8 to 37.4 & 7 (33.3) & 15.5 to 26.9 \\
\hline Other ${ }^{\star}$ & $1(4.8)$ & 0.3 to 25.9 & 0 & & $1(4.8)$ & 0.3 to 25.9 \\
\hline Total & 21 & & $11(52.4)$ & & $10(47.6)$ & \\
\hline
\end{tabular}

*Injury which cannot be attributed to a single match or training incident.

(SD 3.6) years. Their mean height was 1.68 (SD 0.06) $\mathrm{m}$ and their mean weight was 64.83 (SD 6.25) kg. Mean body mass index was 22.8 (SD 1.9) $\mathrm{kg} / \mathrm{m}^{2}$. Twenty-eight $(45.16 \%)$ of the participants were full-time students.

During the study, 21 injury incidents were recorded, with 14 (23\%; $95 \%$ CI $14 \%$ to $34 \%$ ) of the 62 players injured in total, a measure of overall injury proportion. Eight players (13\%) sustained one injury and six $(10 \%)$ had multiple injuries; one player $(2 \%)$ sustained three injuries and five players (8\%) sustained two injuries.

The 21 injuries were recorded over 2769 hours of match play and training. The incidence of injury was 26.4 (95\% CI 13.44 to 47.16 ) per 1000 hours of match play and 4.2 (95\% CI 2.12 to 7.46$)$ per 1000 hours of training (table 1).

The mean number of injuries per team over the 11 weeks was 7 (SD 1.73) while the mean number of injuries per team per week was 0.64 (SD 0.82) ranging from 0 to 3. The mean time loss per injury was 12.14 (SD 12.5) days ranging from 3 days to 56 days. The mean number of matches missed by injured players was 0.8 (SD 1.7) and mean number of training sessions missed per injured player was 4.1 (SD 6.3). The team injury burden, that is, mean number of player days unavailable for training or matches per team over the 11 weeks was 84.98 days.

There were 11 (52.4\%; $95 \%$ CI $30.3 \%$ to $73.6 \%)$ contact injuries; 6 occurred at club matches, 2 at intercounty matches and 3 at training. There were 10 (47.6\%; $95 \%$ CI $26.4 \%$ to $69.7 \%$ ) non-contact injuries; 7 occurred

\begin{tabular}{|c|c|c|}
\hline & $n(\%)$ & $95 \% \mathrm{Cl}$ \\
\hline Contact & $11(52.4)$ & 30.3 to 73.6 \\
\hline Opponent & $4(19.0)$ & 6.3 to 42.6 \\
\hline Hurley & $3(14.3)$ & 3.8 to 37.4 \\
\hline Ground & $4(19.0)$ & 6.3 to 42.6 \\
\hline Non-contact & $10(47.6)$ & 26.4 to 69.7 \\
\hline Turn/cut & $3(14.3)$ & 3.8 to 37.4 \\
\hline Sprint & $4(19.0)$ & 6.3 to 42.6 \\
\hline Push off & $1(4.8)$ & 0.3 to 25.9 \\
\hline Overuse & $2(9.4)$ & 1.7 to 31.8 \\
\hline 'New' Injury & 13 (61.9) & 38.7 to 81.0 \\
\hline 'Recurrent' Injury & $8(38.1)$ & 19.0 to 61.3 \\
\hline
\end{tabular}

at training, 2 at intercounty matches, while for 1, injury location was not specified. Of the recurrent injuries three were sustained to the Achilles tendon, two to ligaments in the foot/ankle, one to the hamstring, one to the head (concussion) and one was a muscular back spasm (tables 2 and 3 ).

The main body region injured was the lower limb accounting for $71.4 \% \quad(n=15)$ of all injuries, with the thigh responsible for $23.8 \%(\mathrm{n}=5)$ of total injuries. The upper limb accounted for $9.5 \%(n=2)$ of all injuries, with a further $19.1 \%(n=4)$ located in the trunk or the head (table 4).

Hamstring strain and Achilles tenosynovitis were the most prevalent injuries recorded with three incidents (14.3\%) each. Two players suffered a single hamstring strain with one player having a reoccurrence during the 11 weeks. One player developed a mid-portion Achilles tenosynovitis during the study which represented three separate periods of time out from playing. Ankle sprains and quadriceps contusions accounted for two injuries $(9.4 \%)$ each. There were two incidents of fractures $(9.4 \%)$, one to the ribs and one to a finger.

The main tissues injured were both muscle and ligament, constituting $57.2 \%$ (28.6\%; $95 \%$ CI $12.2 \%$ to $52.3 \%$ each) of total injuries, while tendon, bone and concussion made up the remaining $42.8 \%$.

Table 5 presents details of injured players stratified by positions of play. Goalkeepers had the highest injury risk relative to the other positions.

Of the 62 players followed, 55 self-reported sustaining an injury previously (table 6 ).

Included in the 90 previous injuries to the lower limb were 23 ankle sprains, six anterior cruciate ligament (ACL) ruptures and three posterior cruciate ligament ruptures. Of the 18 previous injuries to the trunk, 6 were concussion injuries.

\section{DISCUSSION \\ Injury rate}

The major finding of this study was that the incidence of injury during camogie match play was 26.4/1000 hours $(95 \%$ CI; 13.44 to 47.16$)$, which is over six times greater than the incidence of injury during camogie training of 4.2/1000 hours (95\% CI; 2.12 to 7.46). As this study used the same injury definition as Brooks et al, direct comparison between camogie and other 


\begin{tabular}{|c|c|c|c|c|c|c|}
\hline Location & Total n (\%) & $95 \% \mathrm{Cl}$ & Contact n (\%) & $95 \% \mathrm{Cl}$ & Non-contact n (\%) & $95 \% \mathrm{Cl}$ \\
\hline Upper Limb & $2(9.5)$ & 1.7 to 31.8 & $2(9.5)$ & 1.7 to 31.8 & $0(0)$ & \\
\hline Hand & $2(9.5)$ & 1.7 to 31.8 & $2(9.5)$ & 1.7 to 31.8 & $0(0)$ & \\
\hline Lower limb & 15 (71.4) & 47.7 to 87.8 & $6(28.6)$ & 12.2 to 52.3 & $9(42.9)$ & 22.6 to 65.6 \\
\hline Thigh & $5(23.8)$ & 9.1 to 37.6 & $2(9.5)$ & 1.7 to 31.8 & $3(14.3)$ & 3.8 to 37.4 \\
\hline Knee & $4(19.0)$ & 6.3 to 42.6 & $3(14.3)$ & 3.8 to 37.4 & $1(4.8)$ & 0.3 to 25.9 \\
\hline Lower leg & $3(14.3)$ & 3.8 to 37.4 & $0(0)$ & & $3(14.3)$ & 3.8 to 37.4 \\
\hline Ankle & $2(9.5)$ & 1.7 to 31.8 & $0(0)$ & & $2(9.5)$ & 1.7 to 31.8 \\
\hline Foot & $1(4.8)$ & 0.3 to 25.9 & $1(4.8)$ & 0.3 to 25.9 & $0(0)$ & \\
\hline Trunk & $4(19.1)$ & 6.3 to 42.6 & $3(14.3)$ & 3.8 to 37.4 & $1(4.8)$ & 0.3 to 25.9 \\
\hline Head & $2(9.5)$ & 1.7 to 31.8 & $2(2.9)$ & 1.7 to 31.8 & 0 & \\
\hline Back & $1(4.8)$ & 0.3 to 25.9 & $0(0)$ & & $1(4.8)$ & 0.3 to 25.9 \\
\hline Trunk & $1(4.8)$ & 0.3 to 25.9 & $1(4.8)$ & 0.3 to 25.9 & 0 & \\
\hline
\end{tabular}

sports is possible. ${ }^{8} 91213162021$ Increased risk of injury during match play compared with training is evident in other field sports such as hurling (61.75/1000 hours vs 2.99/1000 hours), ${ }^{9}$ Gaelic football (61.86/1000 hours vs $4.05 / 1000$ hours $),{ }^{20}$ professional rugby union $(91 / 1000$ hours vs $2 / 1000$ hours $)^{1621}$ and soccer $(23.92 / 1000$ hours vs 3.01/1000 hours). ${ }^{12} 13$ A higher incidence of injury in match play versus training is also evident in women's field sports such as women's soccer (21.79/1000 hours vs $2.79 / 1000$ hours $)^{12} 13$ and women's collegiate field hockey (7.78/1000 hours vs 2.99/1000 hours). ${ }^{22} 23$ These figures reflect the higher intensity and consistently competitive nature of match play across field sports.

\section{Rule and gender differences}

The major difference in rules between camogie and hurling from an injury perspective is that camogie is non-contact, while shoulder to shoulder challenges are permitted in hurling. ${ }^{19}$ This is similar in ice hockey, another stickhandling sport, where body checking is permitted in the men's game at adult level but not in the women's game. ${ }^{11}$ The rule differences which allow physical contact in men's hurling and men's ice hockey surely contributes to the overall higher match injury rate in hurling versus camogie matches $(61.75 / 1000$ hours

\begin{tabular}{lccl}
\hline Table 5 & Position of play \\
\hline $\begin{array}{l}\text { Position of } \\
\text { play }\end{array}$ & $\begin{array}{l}\%(\mathbf{n}) \text { of total } \\
\text { group (n=62) }\end{array}$ & $\begin{array}{l}\text { injured group } \\
(\mathbf{n}=\mathbf{2 1})\end{array}$ & $\begin{array}{l}\text { Risk of injury per } \\
\text { position of play }\end{array}$ \\
\hline Goalkeeper & $8.1 \%(5)$ & $14.3 \%(3)^{\star}$ & $60 \%(3 / 5)$ \\
\hline Defender & $35.5 \%(22)$ & $28.8 \%(5) \dagger$ & $22.7 \%(5 / 22)$ \\
Midfielder & $11.3 \%(7)$ & $4.8 \%(1) \ddagger$ & $14.3 \%(1 / 7)$ \\
\hline Attacker & $45.2 \%(28)$ & $57.1 \%(12) \S$ & $42.9 \%(12 / 28)$ \\
\hline
\end{tabular}

*Goalkeeper 0 upper limb, 1 lower limb, 2 trunk/head injuries. †Defender 1 upper limb, 4 lower limb, 0 trunk/head injuries. ¥Midfielder 0 upper limb, 0 lower limb, 1 trunk/head injuries. §Attacker 1 upper limb, 10 lower limb, 1 trunk/head injuries. vs $26.4 / 1000$ hours $)^{9}$ and in collegiate men's versus women's ice hockey matches $(18.69 / 1000$ athlete exposures vs 12.10/1000 athletic exposures). ${ }^{11}$ Differences in rules between men's and women's versions of the same sport may not be the only cause for a difference in injuries reported. We know in soccer, a sport which has the same rules for men and women, the incidence of injury is similar in men's and women's match play (23.92/1000 hours for men and 21.79/1000 hours for women). ${ }^{12}$ However, the nature of injuries can differ between the population groups, with lower incidence of hamstring and adductor strains and a higher rate of ACL injuries among females. ${ }^{12} 13$ It was interesting to note that in this study, there was no ACL injury, but $9.6 \%$ of players reported having previously ruptured their ACL. It is likely that differences in injury incidence and nature between hurling and camogie is multifactorial, with rule differences and innate gender differences making contributions.

\section{Injury severity and mechanism}

The mean time loss per injury in camogie was 12.14 days, which is similar to hurling's average of 12 days absence from training and match play per injury. 'Recurrent' injuries account for $38 \%$ of injuries in camogie, which is over twice as high as 'recurrent' injuries in hurling $(17 \%) .{ }^{9}$ Eleven of the $21(52.4 \%)$ injuries recorded were contact injuries. Both player-to-player contact and ground contact represented $19 \%$ of total injuries each

Table 6 Previous injuries

\begin{tabular}{llll}
\hline Location & $\begin{array}{l}\text { Total } \\
\mathbf{n}(\%)\end{array}$ & $\begin{array}{l}\text { Fracture } \mathbf{n}(\% \text { of } \\
\text { total injuries) }\end{array}$ & $\begin{array}{l}\text { Non-fracture } \\
\mathbf{n} \text { (\% of total } \\
\text { injuries) }\end{array}$ \\
\hline Upper limb & $60(35)$ & $43(25)$ & $17(10.1)$ \\
Lower limb & $90(53.6)$ & $9(5.4)$ & $81(48.2)$ \\
Trunk & $18(10.7)$ & $4(2.4)$ & $14(8.3)$ \\
\hline
\end{tabular}


and $14.3 \%$ of injuries were from hurley or sliotar contact. Overall, $38.6 \%$ of hurling injuries have been reported to result from player to player contact. ${ }^{9}$ This reflects the higher contact between players in hurling. Approximately $60 \%$ of match injuries in collegiate women's field hockey result from stick or ball contact while $13 \%$ result from player to player contact. ${ }^{22}$ Differences in the stick and the ball between camogie and hockey as well the compulsory wearing of a helmet in camogie may contribute to these differences in injury rates. Protective gloves (ash guards) are available for camogie players to protect from hurley injury to the hand. However, of the 62 players who participated, only two wore ash guards, possibly as wearing ash guards makes catching the sliotar more difficult. Ten of the 21 injuries (47.6\%) were non-contact injuries, $19 \%$ resulting from a sprint, $14.3 \%$ resulting from a cut/turn, $9.5 \%$ resulting from overload and $4.8 \%$ resulting from a push-off. Of these non-contact injuries $77.8 \%$ occurred at training. Similarly, in women's collegiate field hockey the percentage of non-contact injuries at trainings $(64 \%)$ is much higher than in match play (26\%). ${ }^{22}$ This may be due to more skills and fitness work and less contact from opponents, stick/hurley, ball/sliotar and the ground at training sessions compared with match situations.

\section{Body region injured}

The lower limb was most frequently injured, contributing to $71.4 \%$ of all injuries recorded. Of these injuries, $23.8 \%$ were to the thigh, $19 \%$ were to the knee and $9.5 \%$ were to the ankle. These results were similar to hurling where lower limb injuries accounted for $68.3 \%$ of injuries, with the thigh contributing $22.9 \%$, the knee $11.3 \%$ and the ankle 9.3\%. ${ }^{9}$ Lower limb injuries represent a smaller proportion of total injuries in collegiate field hockey (40\% of match injuries and $60 \%$ of training injuries) and surprisingly in ladies' Gaelic football (58\%). ${ }^{1022}$ Like camogie, upper leg muscular strain, ankle ligament strain and knee internal derangement are the most common reasons for injury to the lower limb in collegiate field hockey. ${ }^{22}$ Women's soccer matches on grass surfaces had a higher incidence of lower limb injury $(81.1 \%)$, with the knee and ankle most commonly injured, most likely due to players competing for the ball on the ground with their feet. ${ }^{12}$

Upper limb injuries accounted for only $9.5 \%$ of injuries and were all contact injuries. It is suspected that many of the injuries to the upper limb did not cause an absence from training and hence were not recorded in this study. Studies on other sports report upper limb injures contributing a higher proportion of overall injury, in hurling $(18.6 \%),{ }^{9}$ in women's collegiate field hockey match play $(20 \%)^{22}$ and in ladies' Gaelic football $(23 \%) .{ }^{10}$ Higher levels of physical contact in hurling, a harder ball and stick used in women's hockey and tackling with the hand as opposed to a stick in ladies' Gaelic football may contribute to higher rates of upper limb injury in these sports.

\section{Strengths and limitations}

While camogie is one of the most popular sports in Ireland, to date there is no descriptive injury epidemiology published on the sport. The prospective methodology, standardised injury definitions which agree with international consensus statements and recruitment of chartered physiotherapists to record injury add confidence to this work. An online standardised assessment and data collection system would have added uniformity to data collection, but was not favoured by those collecting data. The amateur status of the game made the study difficult as the researcher was relying on the goodwill of physiotherapists, coaches and players involved. The current study should be interpreted with caution as it's duration did not cover an entire season. This makes comparisons with other studies over the course of a season or multiple seasons limited, as injury incidence usually goes through peaks and troughs at distinct stages within a season. ${ }^{911}$ The time frame was chosen as it encompassed the Provincial Championships and the All-Ireland Championship, before any team was knocked out. This is the premier competition phase in intercounty camogie. Therefore managers, coaches and medical teams wish to prevent or reduce the burden of injury during this stage of the season.

In conclusion, these findings represent a commencement in describing injury profile in camogie, which is the first step van Mechelen et al ${ }^{15}$ used in their 'sequence of prevention' model of sports injuries. It is recommended that injury surveillance over a season or a number of seasons be carried out to get a clearer picture of injury incidence patterns in intercounty camogie.

Acknowledgements The authors wish to acknowledge the physiotherapists and the team managers who facilitated data collection for this paper.

Contributors CSB and CB, the authors, have both contributed to the planning, conduct and reporting of the work described in this project.

Funding This study was part of a Masters in Sports Physiotherapy in UCD. The Camogie Association and the Women's Gaelic Players Association have contributed to funding the publication of this article.

Competing interest None declared.

Patient consent Obatined.

Ethics approval UCD Research Ethics Committee (LS-16-34-Buckley-Blake).

Provenance and peer review Not commissioned; internally peer reviewed.

Data sharing statement Unpublished data which were collected but not reported in this study are available to all those interested in the game of camogie. The principle researcher, CSB, can be contacted by email at info@renabuckleyphysio.ie in relation to these data.

Open Access This is an Open Access article distributed in accordance with the Creative Commons Attribution Non Commercial (CC BY-NC 4.0) license, which permits others to distribute, remix, adapt, build upon this work non-commercially, and license their derivative works on different terms, provided the original work is properly cited and the use is non-commercial. See: http://creativecommons.org/ licenses/by-nc/4.0/

(c) Article author(s) (or their employer(s) unless otherwise stated in the text of the article) 2018. All rights reserved. No commercial use is permitted unless otherwise expressly granted. 


\section{REFERENCES}

1. Chief Executive Officer' Report, The Annual Convention, 2014. (Tuaracáil an Árd Stiúrthóra, An Chomhdháil Bhliantúil, 2014), 2014. http://www.camogie.ie/files/Downloadable\%20Documents/ Camogie\%20Congress\%202014.pdf (accessed 01 Feb 2016).

2. Indecon International Economic Consultants. In association with the sport industry research centre, Sheffield-Hallam University November 2010 Assessment of Economic Impact of Sport in Ireland Submitted to The Irish Sports Council.

3. The Camogie Association, Official Guide Part 2 Official Playing Rules, 2015. http://www.camogie.ie/files/Playing\%20Rules\% 202015.pdf (accessed 01 Feb 2016).

4. The highs and lows of the 2015 camogie championship, 2015 https://www.libertyinsurance.ie/blog/camogie-championshipseason-2015/ (accessed 01 Feb 2016).

5. Meeuwisse WH, Tyreman $\mathrm{H}$, Hagel $\mathrm{B}$, et al. A dynamic model of etiology in sport injury: the recursive nature of risk and causation. Clin J Sport Med 2007;17:215-9.

6. Wong $\mathrm{P}$, Hong Y. Soccer injury in the lower extremities. Br J Sports Med 2005;39:473-82.

7. Crowley PJ, Condon KC. Analysis of hurling and camogie injuries. $\mathrm{Br}$ $J$ Sports Med 1989;23:183-5.

8. Murphy JC, Gissane C, Blake C. Injury in elite county-level hurling: a prospective study. Br J Sports Med 2012;46:138-42.

9. Blake C, O'Malley E, Gissane C, et al. Epidemiology of injuries in hurling: a prospective study 2007-2011. BMJ Open 2014;4:e005059.

10. Crowley J, Jordan J, Falvey E. A comparison of Gaelic football injuries in males and females in primary care. Ir Med $J$ 2011;104:268-70.

11. Agel J, Harvey EJ. A 7-year review of men's and women's ice hockey injuries in the NCAA. Can J Surg 2010;53:319.

12. Fuller CW, Dick RW, Corlette J, et al. Comparison of the incidence, nature and cause of injuries sustained on grass and new generation artificial turf by male and female football players. Part 1: match injuries. Br J Sports Med 2007;41(Suppl I):i20-6.
13. Fuller CW, Dick RW, Corlette J, et al. Comparison of the incidence, nature and cause of injuries sustained on grass and new generation artificial turf by male and female football players. Part 2: training injuries. Br J Sports Med 2007;41(Suppl I):i27-32.

14. Fédération Internationale de Football Association, 2015. https:// www.fifa.com/mm/Document/FootballDevelopment/Refereeing/ 02/36/01/11/LawsofthegamewebEN_Neutral.pdf (accessed 15 Jun 2017).

15. van Mechelen W, Hlobil H, Kemper HC. Incidence, severity, aetiology and prevention of sports injuries. A review of concepts. Sports Med 1992;14:82-99.

16. Brooks JH, Fuller CW, Kemp SP, et al. Epidemiology of injuries in English professional rugby union: part 1 match injuries. $\mathrm{Br} J$ Sports Med 2005;39:757-66.

17. Fuller CW, Ekstrand J, Junge A, et al. Consensus statement on injury definitions and data collection procedures in studies of football (soccer) injuries. Br J Sports Med 2006;40:193-201.

18. Fuller CW, Molloy MG, Bagate $\mathrm{C}$, et al. Consensus statement on injury definitions and data collection procedures for studies of injuries in rugby union. Br J Sports Med 2007;41:328-31.

19. Gaelic Athletic Association, 2016. http://www.gaa.ie/mm/Document/ TheGAA/RulesandRegulations/12/66/56/2016OfficialGuide-Part2_ English.pdf (accessed15 Jun 2017).

20. Murphy JC, O'Malley E, Gissane C, et al. Incidence of injury in Gaelic football: a 4-year prospective study. Am J Sports Med 2012;40:2113-20.

21. Brooks JH, Fuller CW, Kemp SP, et al. Epidemiology of injuries in English professional rugby union: part 2 training Injuries. $\mathrm{Br} J$ Sports Med 2005;39:767-75.

22. Dick R, Hootman JM, Agel J, et al. Descriptive epidemiology of collegiate women's field hockey injuries: National Collegiate Athletic Association Injury Surveillance System, 1988-1989 through 2002 2003. J Athl Train 2007;42:211-20.

23. Dick R, Agel J, Marshall SW. National Collegiate Athletic Association Injury Surveillance System commentaries: introduction and methods. J Athl Train 2007;42:173-82. 